\title{
"Natural family planning": effective birth control supported by the Catholic Church
}

\author{
RE J Ryder
}

During 20-22 September Manchester is to host the 1993 follow up to last year's "earth summit" in Rio de Janeiro. At that summit the threat posed by world overpopulation received considerable attention. Catholicism was perceived as opposed to birth control and therefore as a particular threat. This was based on the notion that the only method of birth control approved by the church-natural family planning-is unreliable, unacceptable, and ineffective.

In the 20 years since $E$ L Billings and colleagues first described the cervical mucus symptoms associated with ovulation natural family planning has incorporated these symptoms and advanced considerably. Ultrasonography shows that the symptoms identify ovulation precisely. According to the World Health Organisation, 93\% of women everywhere can identify the symptoms, which distinguish adequately between the fertile and infertile phases of the menstrual cycle. Most pregnancies during trials of natural family planning occur after intercourse at times recognised by couples as fertile. Thus pregnancy rates have depended on the motivation of couples. Increasingly studies show that rates equivalent to those with other contraceptive methods are readily achieved in the developed and developing worlds. Indeed, a study of 19843 poor women in India had a pregnancy rate approaching zero. Natural family planning is cheap, effective, without side effects, and may be particularly acceptable to and efficacious among people in areas of poverty.

The 1993 follow up to last year's "earth summit" in Rio de Janeiro is to take place in Manchester during 20-22 September and is entitled "Partnerships for change." The Rio earth summit focused considerable attention on the expanding population of the world as an important issue in relation to resources, environment, and poverty. In the media the "opposition of the Catholic Church to birth control" was discussed (BBC Radio 4, Today Programme, 18 May 1992) and considered to be an important factor with the many millions of Catholics in the world, particularly the Third World, such as Brazil. In the medical press the "Pope's continuing opposition to birth control" was condemned $^{1}$ and powerful Vatican opposition was considered likely to wreck hope of useful progress at the earth summit with regard to global overpopulation as a most urgent ecological hazard. ${ }^{2}$

The widespread beliefs that the Catholic Church is opposed to birth control, ${ }^{1}$ that the urgent provision of artificial contraception within the Third World is the only answer to overpopulation, and that the Catholic Church is opposed to this ${ }^{2}$ all stem from the perception that the so called "natural methods of family planning," which are approved by the Catholic Church, are unreliable, unacceptable, and ineffective. Historically, this perception is based on the unreliability of the rhythm method of contraception ("Roman roulette"), which attempts to identify the fertile phase of the woman's cycle by calendar calculations. Is this perception as accurate today as it may have been in the past?

The ovum has a life span of not more than 24 hours and is fertilisable for only part of that time. ${ }^{3}$ The life span of the sperm may be measured in hours under adverse conditions. Under optimum conditions, however, sperms may remain viable for four or five days, and a life span of up to seven days has been postulated. Thus a woman is potentially fertile for no more than six to eight days of her cycle, probably less in most cases. To what extent can these potentially fertile days be accurately identified and avoided by most women as a method of birth control?

\section{Cyclical changes in cervical mucus secretion}

In 1972 Billings et al reported the characteristic changes in cervical mucus secretion which occur during the menstrual cycle. ${ }^{4}$ After menstruation there are a variable number of "dry" days with little or no mucus secretion and a feeling of dryness in the vaginal area. Then, as ovulation approaches under the influence of increasing oestrogen concentrations ${ }^{35}$ the dry feeling ends and there is increasing secretion of cervical mucus, which at the time of ovulation becomes an abundant discharge of substance like the raw white of an egg. After ovulation the first secretion of progesterone abruptly reverses the effect of oestrogen on cervical mucus and causes it to become thick and rubbery, forming a plug in the cervix. ${ }^{35}$ The fertiletype, "raw egg white" cervical mucus is of low viscosity and high threadability (spinnbarkeit) with glycoprotein fibrils in a micelle-like structure which aids sperm migration. It contains sugars and trace elements necessary for sperm survival, capacitation, and transport and it can maintain the sperm capable of fertilisation for several days. ${ }^{356}$ By contrast, the thick, white, non-stretchy mucus which occurs at other times in the cycle is impenetrable by sperm and hostile to its survival.

Other symptoms have been described in association with ovulation, in particular periovulatory pain and the progesterone induced postovulatory rise in basal body temperature. Hormonal studies have confirmed the close relation of the various symptoms with ovulation, ${ }^{47}$ and more recently ovarian ultrasonography has suggested that the day of most abundant secretion of fertile-type egg white mucus identifies the day of ovulation as precisely as does the luteinising hormone peak (see figure). ${ }^{8}$ Other symptoms associated with the cyclical changes in oestrogen and progesterone concentrations include changes in the cervix, breast tissue, skin, hair, libido, and moods. ${ }^{35}$ 


\section{Pregnancy and contraception}

Reported pregnancy rates (pregnancies per 100 woman years; Pearl index) in well motivated couples using the condom, diaphragm, intrauterine device, and progestogen only and combined oestrogenprogestogen oral contraception are $3.6,1.9,1.4,1.2$, and 0.18 respectively. ${ }^{9}$ Much higher rates have been recorded, particularly among less motivated couplesfor example, pregnancy rates of 21 and 22 in condom users $^{10}$ and 23 in diaphragm users. ${ }^{10}$ Pregnancy rates of 23 and 28 have also been reported in users of oral contraceptives in the developing world. ${ }^{11}$ As shown in Oxford, even the contraceptive pill may fail if the woman forgets to take it, runs out of tablets, or has diarrhoea and vomiting or other illness. ${ }^{12}$

Early trials of birth control based on symptom observation $^{13-17}$ yielded pregnancy rates of $6 \cdot 0^{17}$ to $25 \cdot 4 .^{13}$ Most conceptions occurred because of intercourse on days designated by the family planning method as fertile. Controversy therefore ensued ${ }^{18-21}$ between those who thought that all pregnancies occurring in trials should be considered as failures of the particular method ${ }^{1921}$ and those who thought that the method could not be blamed if couples had intercourse during a phase which they knew to be fertile. ${ }^{1820}$ It was also possible that initial scepticism about natural family planning methods led to a casual approach by couples. ${ }^{13}$

\section{WHO study}

Given a natural pregnancy rate-that is, the Pearl index without any birth control-estimated as $80,{ }^{22}$ the cheapness of natural family planning, and the acceptability of natural family planning to many cultures and religions, the World Health Organisation undertook an international study ${ }^{23-27} \mathrm{~A}$ total of 869 women of proved fertility and widely varying cultural, educational, and economic backgrounds were studied in five centres (Auckland, Bangalore, Dublin, Manila, and San Miguel, El Salvador). Regardless of culture and education, $93 \%$ of the women recorded an interpretable ovulatory mucus pattern. Of the El Salvador women, $48 \cdot 1 \%$ were illiterate and yet recognised the mucus symptoms. ${ }^{23}$

Detailed analysis in the WHO study confirmed the potential effectiveness of mucus symptom observation as a means of family planning. The probability of conception from intercourse outside the period of fertility defined by cervical mucus observation was 0.004 (see table). ${ }^{25}$ Intercourse on days designated as fertile by cervical mucus observation resulted in conception with increasing frequency the nearer to ovulation that intercourse occurred, intercourse on the peak day of cervical mucus secretion resulting in a probability of conception of 0.667 (table). ${ }^{25}$ Thus it is clear that women of all cultures and educational backgrounds can learn to recognise when they ovulate

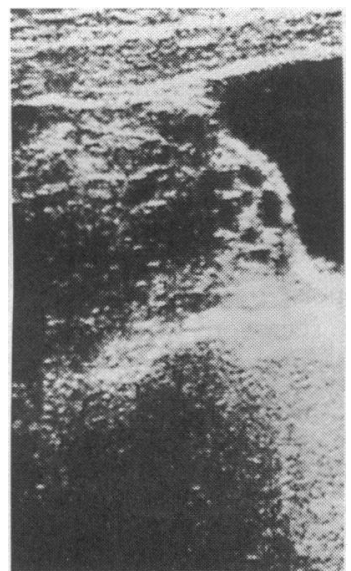

Scan A. Early follicular phase Normal ovary early in menstrual cycle. Scan shows multiple follicles each of 8-10 mm diameter. No single follicle dominant

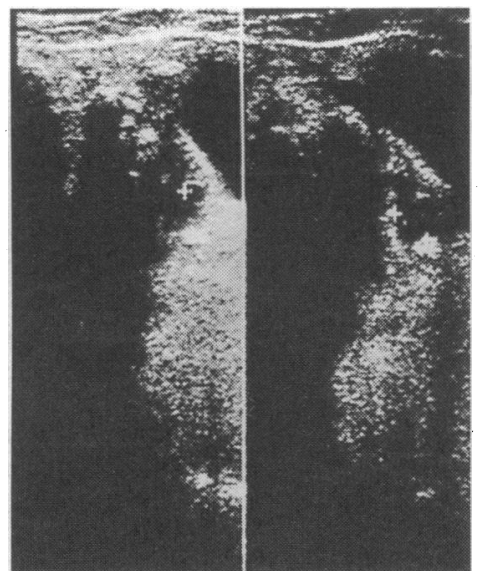

Scan B. Day 12

View of right ovary. Dominant follicle $14 \mathrm{~mm}$ diameter visible on right, between the two crosses

Symptoms-Feeling of wetness; no mucus visible Temperature $36 \cdot 2^{\circ} \mathrm{C}$

Luteinising hormone $12 \cdot 4 \mathrm{U} /$

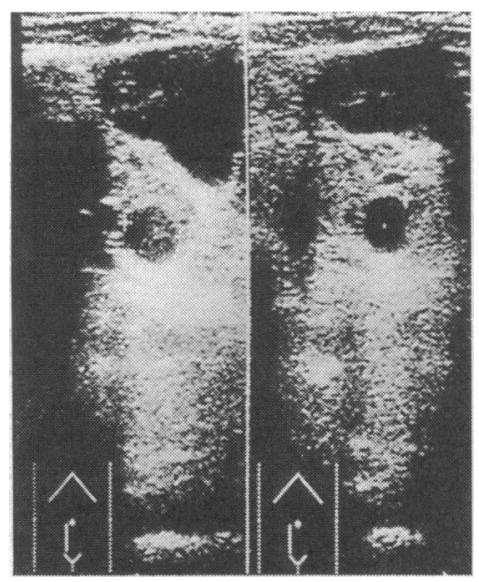

Scan E. Day 17

Follicle $22 \mathrm{~mm}$ maximum diameter. Ovulation would be expected shortly

Symptoms-Abundant clear, slippery mucus. Pain

Temperature $36.5^{\circ} \mathrm{C}$

Luteinising hormone $>51.5 \mathrm{UA}$

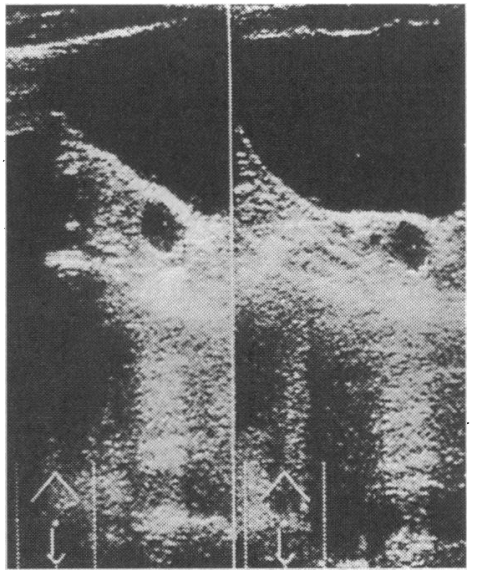

Scan C. Day 15

Views of same follicle as in scan B. Follicle now $20 \mathrm{~mm}$ maximum diameter (left view) Symptoms-Moderate amount of clear, slippery mucus

Temperature $36.5^{\circ} \mathrm{C}$

Luteinising hormone $11.8 \mathrm{U} / 1$

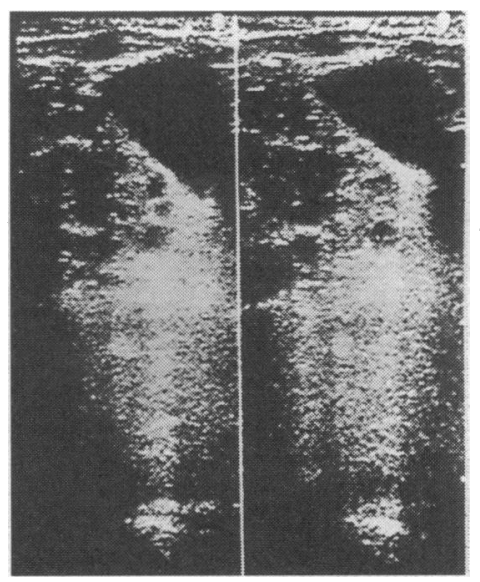

Scan F. Day 18

Follicle has collapsed, leading to corpus luteum (two views). Maximum diameter now $15 \mathrm{~mm}^{1}$ Symptoms-Clear, slippery mucus less than on day 17. Pain

Temperature $36.4^{\circ} \mathrm{C}$

Luteinising hormone not sampled

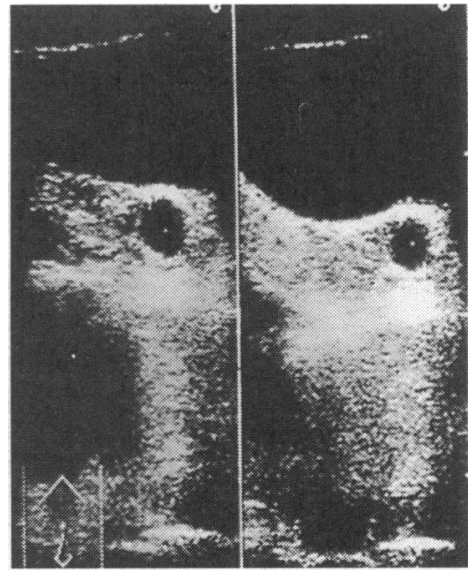

Scan D. Day 16

Follicle $21 \mathrm{~mm}$ maximum diameter (left view) Symptoms - Greater amount of clear, slippery mucus. Pain

Temperature $36.4^{\circ} \mathrm{C}$

Luteinising hormone $23.8 \mathrm{U} /$

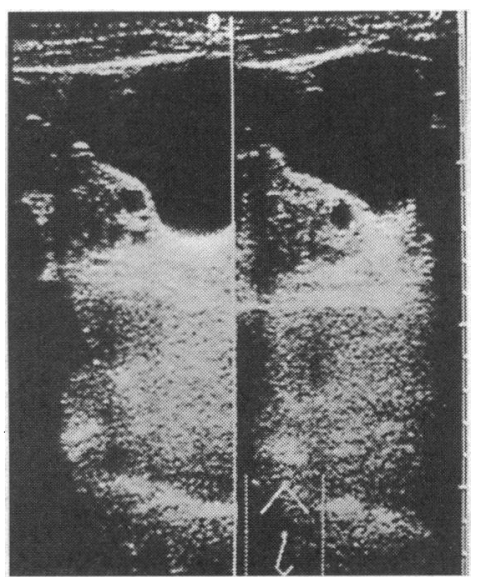

Scan G. Day 19

Corpus luteum (right view) $11 \mathrm{~mm}$ diameter

Symptoms-Reduced amount of moist, sticky, cloudy mucus. Basal body temperature rise $0.3^{\circ} \mathrm{C}$ Temperature $36.7^{\circ} \mathrm{C}$

Luteinising hormone $15 \cdot 1 \mathrm{U} /$ 
Probability of pregnancy by phase of cycle and days from last day of fertile-type cervical mucus (peak day)

\begin{tabular}{llccc}
\hline Phase of cycle & \multicolumn{1}{c}{ Relation to peak day } & $\begin{array}{c}\text { Cycles with } \\
\text { intercourse }\end{array}$ & $\begin{array}{c}\text { No of } \\
\text { pregnancies }\end{array}$ & $\begin{array}{c}\text { Probability of } \\
\text { pregnancy }\end{array}$ \\
\hline Sticky mucus & Peak day -4 or earlier & 81 & 2 & 0.024 \\
Sticky mucus & Peak day - 3 to peak day -1 & 6 & 3 & 0.500 \\
Slippery mucus & Peak day -4 or earlier & 17 & 6 & 0.353 \\
Slippery mucus & Peak day -3 to peak day -1 & 22 & 12 & 0.546 \\
Peak day & Peak day 0 & 9 & 6 & 0.667 \\
Postpeak & Peak day -1 & 18 & 8 & 0.444 \\
Postpeak & Peak day -2 & 44 & 9 & 0.205 \\
Postpeak & Peak day -3 & 112 & 10 & 0.089 \\
Outside fertile period & - & 6158 & 22 & 0.004 \\
\hline All phases & - & 6467 & 78 & 0.012 \\
\hline
\end{tabular}

Data from WHO international study of natural family planning. ${ }^{25}$

and when they are potentially fertile and that if intercourse is avoided on potentially fertile days pregnancies will not occur.

\section{Increased confidence in natural contraception}

After the early studies, ${ }^{13-17}$ increased confidence in and experience with natural family planning methods tended to lead to progressively lower overall pregnancy rates. The rates, however, remain variable, depending on the standard of teaching and the motivation to avoid pregnancy. ${ }^{24-39} \mathrm{~A}$ study in Chile confirmed the importance of good initial natural family planning teaching, experienced teachers achieving a pregnancy rate of $4 \cdot 7$, inexperienced teachers achieving a rate of $16 \cdot 8 .{ }^{28}$ Studies have underlined the importance of motivation, one international study finding a pregnancy rate of $4 \cdot 13$ in couples wishing to limit their families but a rate of 14.56 in couples wishing only to space their families. ${ }^{29}$ Studies suggest that methods combining several indicators of ovulation yield lower pregnancy rates. ${ }^{3}$ The cost issue has been addressed, studies from Liberia and Zambia showing pregnancy rates of 4.3 and 8.9 and user costs of $\$ 40$ and $\$ 30$ respectively. ${ }^{35}$ A study of natural family planning in general practice in the United Kingdom also found it to be by far the cheapest method. ${ }^{39}$

The largest natural family planning study combined effective teaching with high motivation and showed that natural family planning can be extremely effective in the Third World. ${ }^{33}$ The study was of 19843 predominantly poor women in Calcutta, $52 \%$ Hindu, $27 \%$

\begin{tabular}{l} 
Clinical implications \\
\hline Ovarian ultrasonography shows that cervical \\
mucus symptoms identify ovulation with \\
precision \\
- According to the WHO, women of all cultural \\
and educational backgrounds can learn to use \\
cervical mucus symptom observation to recog- \\
nise when they ovulate \\
- Worldwide evidence suggests that methods \\
of birth control using avoidance of the fertile \\
phase identified by ovulation symptoms are \\
associated with pregnancy rates equivalent to \\
those with artificial contraception \\
- Findings among some 20000 poor women in \\
Calcutta with a pregnancy rate approaching \\
zero, complemented by other studies in the \\
developing world, suggest that the motivation of \\
poverty may be particularly associated with \\
effective "natural family planning" \\
- A WHO study found that couples in the \\
developing world were satisfied with the \\
frequency of intercourse associated with natural \\
family planning, which is cheap and may be \\
especially valuable in the developing world \\
\hline
\end{tabular}

Muslim, and $21 \%$ Christian. Because of poverty motivation was high both among the users and among the well trained teachers of natural family planning. The failure rate was similar to that with the combined contraceptive pill -0.2 pregnancy $/ 100$ women users yearly. ${ }^{33}$ The result suggests that poverty as the motivation can greatly improve the effectiveness of natural family planning. A similar result, however, was achieved in Germany in a study with a pregnancy rate of $0 \cdot 8 .^{34}$

An Italian study found an overall pregnancy rate of 3.6 , all the pregnancies occurring in couples wishing to space but not limit their families. The pregnancy rate was zero in couples who wanted no more children..$^{30}$ With other German studies finding pregnancy rates of $1 \cdot 8^{31}$ and $2 \cdot 3,{ }^{36}$ a study in general practice in the United Kingdom finding a rate of $2 \cdot 7,{ }^{39}$ and a study among 3003 illiterate and semiliterate women in India yielding a pregnancy rate of $2 \cdot 04^{37}$ the accumulating data confirm that natural family planning can be as effective as any method of family planning.

\section{Implications for the Third World}

In the WHO study most couples in the three developing countries who practised natural family planning were satisfied with the frequency of intercourse, whereas in the two developed countries one third of subjects and half of their partners who practised the method would have preferred more frequent intercourse. ${ }^{27}$ It might be argued that natural family planning being cheap, effective, without side effects, and potentially particularly effective and acceptable in areas of poverty may be the family planning method of choice for the Third World. The case for and against this may be argued and debated, but whatever the standpoint there is no doubt that it would be more efficient for the ongoing world debate on overpopulation, resources, environment, poverty, and health to be conducted against a background of truth rather than fallacy. It is therefore important that the misconception that Catholicism is synonymous with ineffective birth control ${ }^{12}$ is laid to rest.

Understanding the simple facts about the signs of fertility confers considerable power to couples to control their fertility, for achieving as well as preventing conception. The widespread dissemination of these simple facts would be useful everywhere but might be of particular value in the Third World.

1 Godlee F. Going backwards in Rio. BMF 1992;304:1525.

2 Poole J. Time for the Vatican to bend. Lancet 1992;339:1340-1.

3 Flynn AM. Natural methods of contraception. Maternal and Child Health 1991;16:148-53.

4 Billings EL, Billings JJ, Brown JB, Burger HG. Symptoms and hormonal changes accompanying ovulation. Lancet 1972;i:282-4.

5 France JT. The detection of ovulation for fertility and infertility. In: Bonnar J, ed. Recent advances in obstetrics and gynaecology. Edinburgh: Churchill Livingstone, 1982:215-39.

6 Bromwich PD. Problems with sperm/cervical mucus interaction. Part 1: pathophysiology. British fournal of Sexual Medicine 1985;12:124-5.

7 Flynn AM, Lynch SS. Cervical mucus and identification of the fertile phase of the menstrual cycle. Brf Obstet Gynaecol 1976;83:656-9.

of the menstrual cycle. Br f Obstet Gynaecol 1976;83:656-9.
8 Depares J, Ryder REJ, Walker SM, Scanlon MF, Norman CM. Ovarian Depares J, Ryder REJ, Walker SM, Scanlon MF, Norman CM. Ovarian
ultrasonography highlights precison of symptoms of ovulation as markers of ultrasonography highlights precison
ovulation. $B M \mp$ 1986;292:1562.

9 Vessey $M$, Lawless $M$, Yeates D. Efficacy of different contraceptive methods. Lancet 1982;i:841-2.

10 Mills A. Barrier contraception. Clin Obstet Gynecol 1984;11:641-60.

11 Laing JE. Natural family planning in the Philippines. Stud Fam Plann 1984;15:49-55.

12 Duncan G, Harper C, Ashwell E, Mant D, Buchan H, Jones L. Termination of pregnancy: lessons for prevention. British fournal of Family Planning 1990;15:112-7.

13 Weissman MC, Foliaki L, Billings EL, Billings JJ. A trial of the ovulation method of family planning in Tonga. Lancet 1972;ii:813-6.

14 Ball $M$. A prospective field trial of the ovulation method of avoiding conception. Eur Y Obstet Gynecol Reprod Biol 1976;6:63-6.

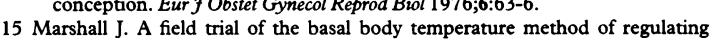
births. Lancet 1968:ii:8-10.

16 Marshall J. Cervical-mucus and basal body temperature method of regulating births. Lancet 1976;ii:282-3.

17 Parenteau-Carreau S, Lanctot CA, Rice FJ. Étude internationale Fairfield sur l'efficacité de la méthode sympto-thermique de régulation des naissances. Résultats Canadiens comparés aux résultats globaux. La Vie Médicale au Canada Frangais 1976;4:145-53. 
18 Billings JJ. Natural family planning. Lancet 1976;ii:579.

19 Marshall J. Natural family planning. Lancet 1976;ii:685.

20 Billings J. Natural family planning. Lancet 1976;ii:969.

21 Marshall J. Natural family planning. Lancet 1976;ii: 1085

22 Reid KM. Choice of method. In: Loudon N, ed. Handbook of family planning. Edinburgh: Churchill Livingstone, 1985:25-39.

23 World Health Organisation. A prospective multicentre trial of the ovulation method of natural family planning. I. The teaching phase. Fertil Steril 1981;36:152-8.

24 World Health Organisation. A prospective multicentre trial of the ovulation method of natural family planning. II. The effectiveness phase. Fertil Steril 1981;36:591-8.

25 World Health Organisation. A prospective multicentre trial of the ovulation method of natural family planning. III. Characteristics of the menstrual cycle and of the fertile phase. Fertil Steri 1983;40:773-8.

26 World Health Organisation. A prospective multicentre trial of the ovulation method of natural family planning. IV. The outcome of pregnancy. Fertil Steril 1984;41:593-8.

27 World Health Organisation. A prospective multicentre trial of the ovulation method of natural family planning. V. Psychosexual aspects. Fertil Steril 1987;47:765-72.

28 Perez A, Zabala A, Larrain A, Widmer S, Nunez M, Baranda B, et al. The clinical efficiency of the ovulation method (Billings). Rev Chil Obstet Ginecol 1983;48:97-102

29 Rice RJ, Lanctot CA, Garcia-Devesa C. Effectiveness of the symptothermal method of natural family planning: an international study. Int $f$ Fertil 1981;26:222-30.

30 Barbato M, Bertolotti G. Natural methods for fertility control: a prospective study. Int f Fertil 1988;33(suppl):48-51.
31 Frank-Hermann $P$, Bremme $M$, Rosmus $t$, Kunkel W. Use-effectiveness of a symptothermal method in Germany. In: Schaitouits H, ed. Proceedings of 4th European congress IFFLP/FIDAF Vienna, Austria. Vienna: Institut für 4th European congress IFFLP/FIL

32 Bonnar J. Natural family planning including breast feeding. In: Mishell DR, ed. Advances in fertility research. New York: Raven Press, 1982:1-18.

33 Ghosh AK, Saha S, Chattergee G. Symptothermia vis a vis fertility control. foumal of Obstetrics and Gynaecology of India 1982;32:443-7.

34 Roetzer J. Symptothermal methods of natural family planning. International Review of Natural Family Planning 1981;5:200-2.

35 Kambic RT, Gray RH, Lanctot CA, Martin MC, Wesley R, Cremins R. Evaluation of natural family planning programs in Liberia and Zambia. Am $\mathcal{F}$ Obstet Gynecol 1991;165:2078.

36 Frank-Herrmann P, Freundl G, Burr S, Bremme M, Doring GK, Godehardt EAJ, et al. Effectiveness and acceptability of the symptothermal method of natural family planning in Germany. Am f Obstet Gymecol 1991;165:2052-4.

37 Dorairai K. The modified mucus method in India. Am 7 Obstet Gynecol 1991;165:2066-7.

38 Kelly J. Audit of health services in Gurage. F Trop Pediatr 1992:38:206-7.

39 Clubb EM, Pyper CM, Knight J. A pilot study on teaching natural family planning in general practice. In: Natural family planning: current knowledge and new strategies for the 1990s. Washington, DC: Georgetown University, 1990:130-2.

40 Ryder REJ, Depares J, Norman C, Walker S, Scanlon MF. Ovarian ultrasonography and the precision of the symptoms of ovulation. Clin Sci 1985;69(suppl 12):17P.

(Accepted 28 fuly 1993)

\section{Economic Evaluation and Health Care}

\section{Costs and cost-minimisation analysis}

\section{Ray Robinson}

This is the second in a series of articles that describe the ways in which methods of economic evaluation may be used to assess the economic costs and consequences associated with different forms of health care intervention.
Institute for Health Policy

Studies, University of

Southampton,

Southampton SO9 5NH

Ray Robinson, professor of

health policy

$B M \mathcal{F} 1993 ; 307: 726-8$
Whatever kind of economic evaluation you plan to undertake, the costs must be assessed. In health care these are first of all divided into costs borne by the NHS (like drugs), by patients and their families (like travel), and by the rest of society (like health education). Next the costs have to be valued in monetary terms; direct costs, like wages, pose little problem, but indirect costs (like time spent in hospital) have to have values imputed to them. And that is not all: costs must be further subdivided into average, marginal, and joint costs, which help decisions on how much of a service should be provided. Capital costs (investments in plant, buildings, and machinery) are also important, as are discounting and inflation. In this second article in the series Ray Robinson defines the types of costs, their measurement, and how they should be valued in monetary terms.

Cost-minimisation analysis is an appropriate evaluation method to use when the case for an intervention has been established and the programmes or procedures under consideration are expected to have the same, or similar, outcomes. In these circumstances, attention may focus on the cost side of the equation to identify the least costly option.

The analysis of costs that forms the basis of costminimisation analysis is common to all forms of economic evaluation, and so the following discussion will apply also to applications of cost-effectiveness, cost-utility, and cost-benefit analysis.

\section{Which costs should be included?}

If the evaluation is being made from the widest perspective-namely, the viewpoint of society as a whole-then three main categories of costs must be considered:

- Health service costs

- Costs borne by patients and their families

- External costs borne by the rest of society.

\begin{tabular}{l} 
Summary \\
\hline - Cost-minimisation analysis should be used when \\
the outcomes of alternative programmes are the same \\
or similar \\
- From a societal perspective, costs include: health \\
service costs, costs borne by patients and their families \\
and external costs borne by the rest of society \\
- Costs should reflect opportunity costs and may be \\
valued in terms of market prices or shadow prices \\
- Marginal costs are often lower than average costs \\
- Discounting is necessary to express costs on a \\
common basis (present values) when they are incurred \\
at different points in time \\
- Methods for taking account of inflation need to \\
distinguish between changes in the general price level \\
and changes in relative prices
\end{tabular}

\section{HEALTH SERVICE COSTS}

These will include staff time, medical supplies (including drugs), hotel services, use of capital equipment, and overheads such as heating and lighting. These items may be divided into variable costs which vary according to the level of activity (for example, staff time) and fixed costs which are incurred whatever the level of activity (for example, heating and lighting) In the long run, practically all costs become variable because those that are fixed in the short run may be varied-for example, by opening and closing wards, and by building new hospitals. In economic evaluation all health service costs-both fixed and variable-are referred to as direct costs.

\section{COSTS BORNE BY PATIENTS AND THEIR FAMIIIES}

These will include out of pocket expenses such as travel, and any costs resulting from caring activities undertaken by the family. These are both direct cost items. In addition, there may also be indirect costs such as income lost because of absence from work 